\title{
Factors associated with Immunisation coverage in children of migrant brick kiln workers in selected districts of Bihar, India
}

\section{Pragya Kumar ${ }^{1}$, Alok Ranjan², Dhananjay Kumar ${ }^{3}$, Sanjay Pandey ${ }^{4}$, CM Singh ${ }^{5}$, Neeraj Agarwal ${ }^{6}$}

${ }^{1}$ Additional Professor, Department of Community and Family Medicine, All India Institute of Medical Sciences (AlIMS), Patna, Phulwarisharif-801505, Bihar, India ${ }^{2}$ Assistant Professor, Department of Community and Family Medicine, All India Institute of Medical Sciences (AIIMS), Patna, Phulwarisharif-801505, Bihar, India ${ }^{3}$ Assistant Professor and Head, Palamu Medical College, Palamu ${ }^{4}$ Additional Professor, Department of Community and Family Medicine, All India Institute of Medical Sciences (AlIMS), Patna, Phulwarisharif-801505, Bihar, India 5 Professor, Department of Community and Family Medicine, All India Institute of Medical Sciences (AlIMS), Patna, Phulwarisharif-801505, Bihar, India ${ }^{6}$ Professor \& Head, Department of Community and Family Medicine, All India Institute of Medical Sciences (AIIMS), Patna, Phulwarisharif-801505, Bihar, India

\begin{tabular}{|c|c|c|c|c|c|c|c|}
\hline Abstract & Introduction & Methodology & Results & Conclusion & References & Citation & Tables / Figures \\
\hline \multicolumn{8}{|c|}{ Corresponding Author } \\
\hline \multicolumn{7}{|c|}{$\begin{array}{l}\text { Dr Dhananjay Kumar, Assistant Professor and Head, Palamu Medical College, Palamu. } \\
\text { E Mail ID: } \underline{\text { djkum2k4@gmail.com }}\end{array}$} & 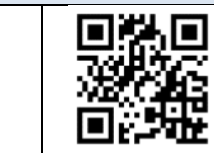 \\
\hline
\end{tabular}

\section{Citation}

Kumar P, Ranjan A, Kumar D, Pandey S, Singh CM, Agarwal N. Factors associated with Immunisation coverage in children of migrant brick kiln workers in selected districts of Bihar, India. Indian J Comm Health. 2020;32(1):91-96.

Source of Funding: This work was supported by Ford Foundation Research Grant by the Indian Association of Preventive and Social Medicine. Conflict of Interest: None declared

\section{Article Cycle}

Received: 04/03/2020; Revision: 08/03/2020; Accepted: 19/03/2020; Published: 31/03/2020

This work is licensed under a Creative Commons Attribution 4.0 International License.

\section{Abstract}

Brick kiln workers are unskilled labourers and keep migrating from one place to another leading to non/partial immunization of their children. The study was conducted to estimate the prevalence of full immunisation among the children of mother living in brick kiln and to assess the factors associated with incomplete or non-immunisation. Methods: The study was conducted using stratified cluster sampling technique in different brick kilns of four districts of Bihar. Results: Out of 332 children the prevalence of full immunization was $55.43 \%$ and partial immunization was $37.65 \%$ while $6.92 \%$ children were not immunized at all. The most common reason for non/partial immunization was lack of awareness about importance of immunization (37.2\%) followed by no information of nearest place of vaccination (33.1\%). Conclusion: The routine immunization coverage has increased but it is still low among migrant brick kiln workers.

\section{Keywords}

Brick kiln; Migrants; Non-immunization; Partial Immunization; Bihar

\section{Introduction}

Universal Immunisation Programme (U.I.P.) in India is one of the largest public health programmes in the world in terms of various factors such as quantities of vaccine used, number of beneficiaries, number of immunisation session organised, geographical spread, and diversity of areas covered. However, there are certain sections of the society such as migrant population who do not receive the full benefits of this public health facility, and hence, there may be significant mortality due to vaccine preventable diseases among them. It is estimated that a high proportion of children living in developing countries die every year due to vaccine preventable diseases (VPD)s out of total mortality of nearly 3 million at the global level. $(1,2)$

Millennium Development Goal -4 was aimed to achieve a reduction of two-third of under-five mortality rate (U5MR) by the year 2015. $(3,4,5)$

The Expanded Programme on Immunization (EPI) was launched in 1974 which subsequently helped in increasing immunization coverage from merely $5 \%$ to $84 \%$ for Diptheria, Tetanus and Pertusis (DPT3) in 2013. (6) Immunization programme has a great impact on reducing morbidity and mortality among children thus averting 2 to 3 million deaths yearly at the global level and preventing illness and disability from vaccine preventable diseases. $(7,8)$ 
However, due to certain socio-cultural and geographical factors, the immunization programme failed to cover all the potential children. It is estimated that nearly 22.6 million children have not been covered by the routine immunization programme $(9,10)$.

A brick kiln is a place where bricks are made, and a large number of seasonal migrant workers come to work during the dry season. Hundreds of such families work in brick kilns in Bihar, coming from other states like Jharkhand, West Bengal and Assam. These migrant workers family keep on moving from one place to another in search of livelihood. As a result, their children often miss routine immunization. The general health services are designed to cater to the native population of a particular area. However, there are gross inequities in the healthcare delivery between the native population and the migrants. The only ad-hoc approach is followed for seasonal migrants.

Low income and uncertainties of jobs at these brick kilns compel the parents to change their job very frequently from one place to other. Relocating residence could be a possible reason for lack of immunization among these children. $(11,12)$. Low income also causes malnutrition among these children. Hence these factors could lead children of brick kilns workers at high risk for vaccine preventable diseases.

All the health workers involved in the routine immunization programme are assigned stipulated areas for the immunization of children living in those designated geographical areas. Consequently, children belonging to urban slums and migrants such as brick-kiln workers are not usually covered in routine immunization leading to a low proportion of immunization coverage among them.

(13)

In order to improve proper immunization among all children including migrants in remote accessible areas and urban slums, the Year 2012 was declared as "the year of intensification of routine immunization" a campaign-like strategy of Government of India. $(14,15)$

Lack of awareness about immunization, session sites and lack of faith in the health workers were important reasons for not giving immunization. (16)

\section{Aims \& Objectives}

This study was conducted to estimate the prevalence of full immunisation among the children of mothers living in brick kiln and to assess the factors associated with incomplete or non-immunisation.

\section{Material \& Methods}

The study was a population based cross sectional study conducted in four districts (Patna, Nalanda, Bhojpur and Vaishali) of Bihar for a period of one year. The sample size calculated was 234 using the formula $\mathrm{N}=(\mathrm{Z} \alpha) 2 \mathrm{P}$ Q/L2, where $\mathrm{Z} \alpha$ for $5 \% \alpha$ error is 1.96 , prevalence of full immunization among children i.e.0.30 (based on findings of Anand S et al) that the level of full immunization among migrant children was $30 \%$. (17) Stratified cluster sampling technique was adopted for the selection of brick kiln hence to allow for the design effect a multiplication factor of 1.5 was used. Thus, the final sample size came out to be 350 children.

The study was conducted in 4 districts of Bihar which are Patna, Vaishali, Bhojpur and Nalanda. District wise list of the total brick kiln was obtained from the Labour Department, Government of Bihar for preparing a sampling frame. Each selected district was taken as a stratum and within each stratum appropriate number of primary selection unit i.e. brick kilns were selected as per the proportional allocation. The brick kiln was taken as a cluster. From each cluster, a minimum 6-7 eligible children were obtained. We took 5 children from each cluster so the desired number of the brick kiln was $350 / 5$ i.e. 70 . So, a total of 70 clusters were taken for the study.

A cross sectional survey of 350 migrant children (12-23 months old) was conducted. Demographic, socioeconomic, migration history and immunisation status of the children of 12-23 months were elicited from mother using a pretested semi structured questionnaire. The immunisation status of the child was determined from the immunisation card and in its absence; the mother's recall was taken as a confirmation of a vaccine (including the number of doses for each).

\section{Operational definitions:}

Full Immunization: If the child has received BCG, three doses of DPT/Pentavalent vaccine, OPV and Measles (or JE) by 1 year of age were considered fully vaccinated.

Non-Immunization: Failure of a child to receive even a single dose of the vaccines listed above by 1 year of age was considered non immunized.

Partial Immunization: Children who have received vaccine doses between non immunization and full immunization.

\section{Statistical analysis}

Out of 350 children surveyed, 18 children were excluded due to lack of complete information. Hence total data of 332 children were analysed. Statistical analysis was performed using Stata Version 10 (StataCorp, Texas, USA). A cluster analysis module of Stata was used after declaring data as a cluster data. Bivariate analysis was performed using chi-square test for the factors/variables related to non-immunisation. Logistic regression analysis was performed taking those variables having crude odds ratio with a p-value equal to 0.10 for modelling non immunisation.

Ethical clearance: The study was approved by institutional ethical committee of AlIMS Patna. Informed verbal consent was obtained from each participant before interviewing them.

\section{Results}

We analysed data of 332 children for their socio-economic status, immunization status and various reasons for 
non/partial immunization. Around $54 \%$ of children were selected from the brick kiln of Patna district, followed by Vaishali (20.5\%), Nalanda (16.9\%) and Bhojpur (9.0\%). The male children outnumbered female (52.7\% Vs $47.3 \%)$. Most study subjects were Hindu (96.1\%). Most of the children belonged to SC/ST $(94.0 \%)$ category followed by other backward castes (3.3\%) and others (2.7\%). Most of the mothers $(87.7 \%)$ and fathers were illiterate $(78.3 \%)$. $62 \%$ of the children belonged to below poverty line. (18) Most of them had birth order first (33.4\%) followed by second (33.1\%). Among migrant's brick kiln worker $62.6 \%$ were migrated from Jharkhand \& West Bengal. (Table 1)

\section{Status of Immunization}

Immunization card was available to only $16.3 \%$ children BCG coverage was $93 \%$. The coverage of DPT/Pentavalent 1st dose was (85.5\%) while DPT/Pentavalent 2nddose was (78.9\%) and DPT/Pentavalent 3rd dose was (69.6\%). The coverage of measles 1 st dose was $55.4 \%$. The prevalence of full immunization was $55.43 \%$ and partial immunization was $37.65 \%$ while $6.92 \%$ of children were not immunized at all. The coverage of full immunization was maximum in Bhojpur (63.3\%) followed by Patna (59\%), Nalanda (55.4\%) and Vaishali (42.6\%). The prevalence of nonimmunization was maximum in Patna (8.98\%) followed by Nalanda (7.14\%) and Vaishali (2.94\%). (Table2)

Reasons for Non-immunization or Incomplete immunization

The most common reason for non/partial immunization was lack of awareness about the importance of immunization (37.2\%) followed by no information of the nearest place of vaccination (33.1\%) and travelling of child with family (18.9\%). Around $74 \%$ parents had no information about the timing of visit for the next vaccination. (Table 3)

Gender, mother literacy and father literacy had no significant association with non-immunization status in the present study. The birth order of child showed association more towards non-immunization status as the $95 \%$ confidence interval was found to be more than a null association $(p=0.07)$. The odds of children who were nonimmunized with birth order 2 or less was 1.51 in comparison to children with birth order more than 2 . Knowledge about the timing of the next vaccination showed a negative and significant association with nonimmunization status with an odd's ratio of 0.49 $(p=0.0074)$. Children of family living below the poverty line had a high risk of non-immunization in comparison to children with above poverty line with an odd's ratio of 2.1 (95\%Cl: 1.29-3.42; $p=0.0015)$.(Table 4)

Logistic regression model showed that factors like birth order less than or equal to 2 (adjusted $O R=1.47$ (95\% Cl:0.91-2.38); $p=0.057)$ and economic status below poverty line (adjusted $O R=2.13(1.32-3.35 ; p=0.002)$ were found to be associated with high risk of non-immunization whereas knowledge about timing of next visit was found to be associated with low risk of non-immunization (adjusted OR=0.57 (0.34-0.91; $p=0.0011)$. (Table 5)

\section{Discussion}

Socio-demographic characteristics

The male children outnumbered female (52.7\% Vs $47.3 \%$ ) which is similar to the population structure of India. Mostly the families of Scheduled caste and Scheduled tribe were involved as brick kiln workers and around 95\% of them had literacy level below 8th standard, in which most of them were illiterate. Most of them were from neighbouring state i.e. Jharkhand. Lower literacy status and higher poverty level lead them to migrate to a neighbouring state and working as a manual labourer in brick kilns.

\section{Status of Immunisation}

In the recently concluded National Family Health Survey (NFHS) - 4 the total coverage of BCG vaccination was $91.7 \%$ and the coverage of full immunization was $61.7 \%$. The present study shows the BCG coverage as $93.1 \%$ which is almost similar to NFHS-4 findings, but the full immunization coverage is $55.4 \%$ which is lower than NFHS-4 findings (19). This difference may be attributed due to the migrant nature of brick kiln worker and poor immunization coverage at brick kiln places. A study conducted on migrants and brick kiln worker found that around $80 \%$ children were either partially immunized or not immunized at all (16). The proportion of nonimmunized children in their study was $5.2 \%$ which is almost similar to the present study (6.9\%). A study reported around $77 \%$ brick kiln children in Kolkata city were partially immunized (20). BCG to measles dropout rate in the present study was $38 \%$ which is similar to a study reported among migrant workers of Haridwar district (21).

Reasons for Non-immunisation or Incomplete immunisation

Lack of awareness of the need for immunization, awareness but no knowledge that were to go for immunization and travelling during the scheduled time for vaccination was the most common cause for nonimmunization and incomplete immunization. A lower level of literacy status among migrant brick kiln workers leads to low awareness among them. Low awareness level regarding benefits of immunization was one of the main reasons for non/partial immunization similar to studies conducted in a migratory population of Bhopal District. $(17,21)$ Nearly $88 \%$ of the mothers and $78 \%$ of the fathers were illiterate, similar to a study conducted among migrant brick kiln workers of Pune and was found to be a significant factor for non/partial immunization of the children. (16)

The migrant workers were not aware regarding the time of next immunisation and the immunisation centres as it was a new place for them. Few of brick kiln was included in the microplan of routine immunisation but the majority 
of them were not a part of immunisation microplan. The migrant workers revealed that they got only pulse polio immunisation on a regular basis.

Association of Immunisation with various sociodemographic characteristics

The birth order of child shows just a significant association with immunization status in bivariate analysis. The possible explanation of this observation could be that as the number of children increases, the knowledge of mother about child immunization and its importance also increases, which eventually leads to better immunization coverage amongst children with birth order more than two. Advance age of mother had been reported as a positive factor for full immunisation of children as reported by various studies. $(22,23)$. This could be due to greater maturity, increased awareness level and social networking among mothers. Knowledge about timing of next vaccination shows a positive and significant association with immunization status. The children with above poverty line had better immunization status in comparison to children with below poverty line.

Limitations of the study: Immunization cards were present with very few families, so the immunisation status was ascertained based on history and mother recalled. This may lead to recall bias.

\section{Conclusion}

The routine immunization coverage has increased but it is still low among migrant brick kiln workers and this reflects that the migrant population was not reached by the routine government health care delivery system.

\section{Recommendation}

There need of specialized efforts to reach out health care delivery services for marginalized population.

\section{Limitation of the study}

Immunization cards were present with very few families, so the immunization status was ascertained based on history and mother recalled. This may lead to recall bias

\section{Relevance of the study}

The study reveals the gross inequities in the accessibility of immunization services between the native population and the migrant population.

\section{Authors Contribution}

PK: conception and design of study, data collection, analysis and manuscript preparation; AR: analysis and interpretation of study findings; DK: data collection, data analysis and drafting the manuscript; SP, CMS \& NA: Revising the Manuscript for important intellectual content.

\section{Acknowledgement}

We acknowledge the support provided by District Immunization officers of the Patna, Vaishali, Nalanda and Bhojpur Districts of Bihar.

\section{References}

1. Kane $M$, Lasher $H$. "The case for childhood immunization".Children's Vaccine Program at Path. Seattle, WA. 2002; Occasional paper, No.5.

2. Datar A, Mukherji A, \& Sood N. Health Infrastructure and Immunization coverage in rural India. Indian J Med Res 125, January 2007, pp 31-42 .

3. World Health Organisation. MDG 4: reducing child mortality. 2013. http://www.

who.int/topics/millennium_development_goals/child_mortality/e $\mathrm{n} /[$ Accessed on 30th January 2017].

4. United Nations Development Programme. Available at: http://www.undp.org/content/india/[ Accessed on 4th February 2017].

5. Legesse E. and Dechasa W. An assessment of child immunization coverage and its determinants in Sinana District, Southeast Ethiopia. BMC Pediatrics, 2015; 15-31. DOI 10.1186/s12887-0150345-4.

6. World Health Organisation (WHO). Global immunization data. 2014. http://www who.int/immunization/monitoring_surveillance/global_immunizat ion_data.pdf[ Accessed on 30th January 2017].

7. World Health Organisation (WHO). Immunisation. 2014. http://www.who.int/topics/ immunization/en/[ Accessed on 30th January 2017].

8. Mavimbe J, Braa J, Bjune G. Assessing immunization data quality from routine reports in Mozambique. BMC Public Health 2005;5:108.

9. World Health Organisation. Immunisation coverage. 2014. http://www.who.int/ mediacentre/factsheets/fs378/en/ [Accessed on 30th January 2017].

10. Awoh AB, Plugge E. Immunisation coverage in rural-urban migrant children in low and middle-income countries (LMICs): a systematic review and meta-analysis. J Epidemiol Community Health 2016;70:305-311. doi:10.1136/jech-2015-205652

11. Annual Report (2008), Ministry of Health and Family Welfare (MoHFW), Govt. of India. Available at:http://mohfw.nic.in/WriteReadData/l892s/9457038092

AnnualReporthealth.pdf.[Accessed on 30th January 2017].

12. Borhade A. Migrants'(Denied) access to health care in India. UNESCO-UNICEF National Workshop on Internal Migration and Human Development in India. Workshop Compendium, Vol. II: Workshop Papers.

13. Goel S, Bali S, Singh A. Impact of a Short Term Intervention on Health Care Outreach to a Marginal Population in Rural North India. The Internet Journal of Health. 2007; 5 (2).

14. Vashishtha VM, Kumar P. 50 years of immunization in India: Progress and future. Indian Pediatr 2013; 50:111-118.

15. Dutta R, Dekal P, Jain T, Jeyapal DR, Sivakumar K, Ramachandran A. Primary immunization coverage among Migrant children in the age group of 12 to 23 months in Sriperumbudur Taluk, Kanchipuram District. Indian J Comm Health. 2017; 29, 1: 114-117.

16. Vaidya VM, Hanumante NM, JoshiAM, Mahajan S. Immunization Status of Under five children in Migrants from Periurban Areas of Pune. Natl J Community Med 2013;4(3): 457-460.

17. Anand S, Verma $P$, Sinha U, Mahawar P. Evaluation of primary immunization coverage in migratory versus non-migratory labour population of urban area in Bhopal city.Pediatriconcall journal. 2014; 11(2).

18. http://timesofindia.indiatimes.com/india/New-poverty-line-Rs32-in-villages-Rs-47-in-cities/articleshow/37920441.cms

19. National family health survey (NFHS 4) 2015-16. State Fact Sheet Bihar - District Level Household \& Facility Survey. rchiips.org/nfhs/pdf/NFHS4/BR_FactSheet.pdf. [Accessed on 30th January 2017].

20. Biswas T, Mandal PK , Samarendra. Assessment of Health, Nutrition and Immunisation status amongst under -5 children in migratory brick klin population of periurban Kolkata, India .Sudanese journal of public health,January 2011; 6(1): 7-13 
INDIAN JOURNAL OF COMMUNITY HEALTH / VOL 32 / ISSUE NO 01 / JAN - MAR 2020

21. Nath L, Kaur $P$, Tripathi S. Evaluation of the universal immunization program and challenges in coverage of migrant children in Haridwar, Uttarakhand, India. Indian J Community Med 2015;40:239-45

22. Kusuma YS, Kumari R, Pandav CS, Gupta SK. Migration and immunization: determinants of childhood immunization uptake
[Factors associated with] | Kumar P et al among socioeconomically disadvantaged migrants in Delhi, India Tropical Medicine and International Health 2010; 15(11): 13261332

23. Antai D (2010) Migration and Child Immunization in Nigeria: individual- and community-level contexts. BMC Public Health 10:116.

\section{Tables}

\section{TABLE 1 GENERAL SOCIO-DEMOGRAPHIC PROFILE OF STUDY SUBJECTS ( $\mathrm{N}=332$ )}

\begin{tabular}{|c|c|}
\hline Variable & Proportion with $95 \%$ Cl \\
\hline \multicolumn{2}{|l|}{ Gender } \\
\hline Male & $175[52.7,47.3-58.1]$ \\
\hline Female & $157[47.3,41.9-52.7]$ \\
\hline \multicolumn{2}{|l|}{ Religion } \\
\hline Hindu & $319[96.1,94-98.2]$ \\
\hline Others & $13[3.9,1.8-6]$ \\
\hline \multicolumn{2}{|l|}{ Caste } \\
\hline General & $9[2.7,1-4.4]$ \\
\hline Other Backward Class (OBC) & $11[3.3,1.4-5.2]$ \\
\hline Scheduled caste/tribe (SC/ST) & $312[94,91.4-96.6]$ \\
\hline \multicolumn{2}{|l|}{ Mother's education } \\
\hline Illiterate & $291[87.7,84.2-91.2]$ \\
\hline Primary & $18[5.4,3-7.8]$ \\
\hline Middle & $15[4.5,2.3-6.7]$ \\
\hline High school and above & $8[2.4,0.8-4]$ \\
\hline \multicolumn{2}{|l|}{ Father's education } \\
\hline Illiterate & $260[78.3,73.9-82.7]$ \\
\hline Primary & $38[11.4,8-14.8]$ \\
\hline Middle & $23[6.9,4.2-9.6]$ \\
\hline High school and above & $11[3.3,1.4-5.2]$ \\
\hline \multicolumn{2}{|l|}{ Socio-economic status } \\
\hline Above poverty line & $126[38,32.8-43.2]$ \\
\hline Below poverty line & $206[62,56.8-67.2]$ \\
\hline \multicolumn{2}{|l|}{ Birth order of index child } \\
\hline 1st & $111[33.4,28.3-38.5]$ \\
\hline 2nd & $110[33.1,28-38.2]$ \\
\hline $3 r d$ & $61[18.4,14.2-22.6]$ \\
\hline 4th & $24[7.3,4.5-10.1]$ \\
\hline 5th and above & $26[7.8,4.9-10.7]$ \\
\hline \multicolumn{2}{|l|}{ District } \\
\hline Patna & $178[53.6,48.2-59]$ \\
\hline Vaishali & $68[20.5,16.2-24.8]$ \\
\hline Nalanda & $56[16.9,12.9-20.9]$ \\
\hline Bhojpur & $30[9,5.9-12.1]$ \\
\hline \multicolumn{2}{|l|}{ Place from where migrated } \\
\hline Jharkhand/ West Bengal & $208[62.6,57.4-67.8]$ \\
\hline Other part of Bihar & $88[26.5,21.8-31.2]$ \\
\hline Local & $36[10.9,7.5-14.3]$ \\
\hline
\end{tabular}

\section{TABLE 2 IMMUNIZATION STATUS OF STUDY SUBJECTS ( $\mathrm{N}=332$ )}

\section{Variable}

\section{Immunization card}

Available

Not available

Vaccines Coverage

BCG

DPT/Pentavalent and OPV1st dose

DPT/Pentavalent and OPV 2nd dose

DPT/Pentavalent and OPV 3rd dose

Measles 1st dose

\section{N [Percentage with 95\% Cl]}

$54,[16.3,12.3-20.3]$

$278,[83.7,79.7-87.7]$

$93.1[90.4-95.8]$

$85.5[81.7-89.3]$

$78.9[74.5-83.3]$

$69.6[64.7-74.5]$

$55.4[50.1-60.7]$ 


\section{Immunization status Coverage}

Fully immunized

Partially immunized

Non immunized
$55.43[50.1-60.8]$

$37.65[32.4-42.9]$

$6.92[4.2-9.7]$

\section{TABLE 3 REASONS FOR NON/INCOMPLETE IMMUNIZATION AMONG STUDY SUBJECTS (N = 148)}

\begin{tabular}{|l|l|}
\hline Reasons & N [Percentage with 95\% Cl] \\
\hline Reason for non/incomplete immunization $(n=148)$ & $55[37.1,29.3-44.9]$ \\
\hline Aware but not know where and when to go & $49[33.1,25.5-40.7]$ \\
\hline Child was sick & $3[2.1,0.2-4.4]$ \\
\hline Fear of adverse effects following immunization & $4[2.7,0.1-5.3]$ \\
\hline Child was travelling & $28[18.9,12.6-25.2]$ \\
\hline Other & $9[6.1,2.2-10]$ \\
\hline Timing of visit for next vaccination & \\
\hline Yes & $87[26.2,19.1-33.3]$ \\
\hline No & $245[73.8,66.7-80.9]$ \\
\hline
\end{tabular}

TABLE 4 BIVARIATE ANALYSIS OF VARIABLES ASSOCIATED WITH IMMUNIZATION (N = 332)

\begin{tabular}{|c|c|c|c|c|c|}
\hline & $\begin{array}{l}\text { Not/partially } \\
\text { immunized }\end{array}$ & $\begin{array}{l}\text { Fully } \\
\text { immunized }\end{array}$ & $\begin{array}{l}\text { Crude } \\
(95 \% \mathrm{Cl}\end{array}$ & $\begin{array}{l}\text { Mantel-Hanszel } \\
\text { value (one-sided) }\end{array}$ & P- \\
\hline \multicolumn{6}{|l|}{ Gender } \\
\hline Male & 76 & 99 & \multirow[t]{2}{*}{$0.906(0.57-1.43)$} & \multirow{2}{*}{\multicolumn{2}{|c|}{0.656}} \\
\hline Female & 72 & 85 & & & \\
\hline \multicolumn{6}{|l|}{ Birth order } \\
\hline 2 or less & 106 & 115 & \multirow[t]{2}{*}{$1.51(0.93-2.49)$} & \multirow{2}{*}{\multicolumn{2}{|c|}{0.07}} \\
\hline More than 2 & 42 & 69 & & & \\
\hline \multicolumn{6}{|c|}{ Mother literacy } \\
\hline Illiterate & 132 & 159 & \multirow[t]{2}{*}{$1.297(0.63-2.71)$} & \multirow{2}{*}{\multicolumn{2}{|c|}{0.447}} \\
\hline Literate & 16 & 25 & & & \\
\hline \multicolumn{6}{|c|}{ Father literacy } \\
\hline Illiterate & 118 & 142 & \multirow[t]{2}{*}{$1.16(0.66-2.05)$} & \multirow{2}{*}{\multicolumn{2}{|c|}{0.574}} \\
\hline Literate & 30 & 42 & & & \\
\hline \multicolumn{6}{|c|}{ Knowledge about timing of next vaccination } \\
\hline Yes & 30 & 57 & \multirow[t]{2}{*}{$0.49(0.28-0.85)$} & \multirow{2}{*}{\multicolumn{2}{|c|}{0.0074}} \\
\hline No & 118 & 127 & & & \\
\hline \multicolumn{6}{|c|}{ Below Poverty Line } \\
\hline Yes & 105 & 100 & \multirow[t]{2}{*}{$2.13(1.29-3.42)$} & \multirow{2}{*}{\multicolumn{2}{|c|}{0.0015}} \\
\hline No & 42 & 84 & & & \\
\hline
\end{tabular}

TABLE 5 VARIABLES RELATED TO IMMUNIZATION USING A LOGISTIC REGRESSION MODEL (N = 332)

\begin{tabular}{|l|l|l|l|}
\hline Variables & Adjusted ORs & $95 \% \mathrm{Cl}$ & P-value \\
\hline Birth order less than equal to 2 & 1.47 & $0.91-2.38$ & 0.057 \\
\hline Below Poverty Line & 2.13 & $1.32-3.35$ & 0.002 \\
\hline Knowledge about timing of next vaccination & 0.57 & $0.34-0.91$ & 0.0011 \\
\hline
\end{tabular}

$*$ LR chi-square at 3 d.f. $=17.54$, P-value $=0.0005$ 